\title{
FORMULATION OF CRISIS PLANS AND STRATEGIES
}

\author{
Harry Thomas EVANS \\ (CEO, H.T. Evans Inc)
}

\section{Objectives}

A company or corporation's paramount corporate objectives in cases requiring crisis management are to ensure, to the greatest extent possible, the safety and security of its employees and their families, customers, the public at large, as well as the safety of the company's physical assets.

\section{Purpose of a Crisis Management Plan (CMP)}

The purpose of these plans is to assist a company or corporation Crisis Management Team in responding and focusing corporate, regional and international resources to resolve a crisis situation ensuring safety to all personnel and minimum disruption to business operations. This plan should provide an organization and assign responsibilities to crisis management team members. It should outline and clarify specific guidelines and procedures for response, management and resolutions to various types of crisis incidents.

\section{Corporate Crisis Management Team Organization}

The Crisis Management Team organization will reflect 2 (two) key principles:

1. Crisis Management Team structure

2. Strategic decision-making

Initially, corporate, regional and international personnel, in charge of specific functional areas, administrate and coordinate those specific areas. When a crisis occurs, it affects every aspect of a corporation. Therefore, it is imperative that every cell or section be notified of potential problems. If necessary, the team may assemble to identify and assess a crisis situation, identifying short and long-term objectives, 
select options, develop responses, and ensure the implementation of measures that have been agreed upon. This team approach offers the benefit of bringing together diverse perspectives and collective experience in a situational briefing format to address crisis issues at hand.

\section{International Organization}

When a crisis occurs in a venue or country away from the corporate headquarters, it will be more efficient to decentralize decision-making, delegating management, if necessary, to a corporation authority at the location of the crisis situation. A point of contact for each facility will be the operations manager. The International Crisis Management Team will be structured in a way, similar to the corporate model, and will operate under the same functional crisis management guidelines. Corporate Headquarters will be kept duly informed of all relevant crisis intelligence data and will be extensively involved in the decision-making process regarding any and all crises.

\section{Decision-Making}

The Chairman of the Crisis Management Team, or someone acting on his / her behalf, will make final decisions on major issues. The team will report to the Chairman and make recommendations with regard to options and courses of action available. The Chairman will take all recommendations into consideration, but will act unilaterally, should the circumstances so require.

The Crisis Management Decision-Making Process encompasses actions targeted to:

1. Identify the problem.

2. Specify objectives and criteria for choosing a solution.

3. Develop alternatives or strategies.

4. Analyze and compare alternatives / strategies.

5. Select the best course of action.

6. Implement the selected plan.

7. Monitor and register results.

It is based on presumptions, such as:

- Decision-making is a process of selecting one course of action from an array of alternatives to achieve an objective.

- Decision-making is an indispensable part of the management process.

- Effective decisions are made to eliminate the cause(s) of the problem.

- Ineffective decisions attack symptoms and not causes. 
- The decision-maker should examine the impact of the decision on the problem, the soundness of the solution and its workability after implementation.

- An effective decision has the following characteristics:

- It deals with underlying factors rather than superficial symptoms.

- It provides solutions which can be readily applied.

- It identifies short- and long-term contingencies and impacts on the problem.

- It is practical within human, financial and other constraints.

Other characteristics of the decision-making process can be summarized as follows:

- The process is contained in a capsule.

- There are time constraints / little time to review.

- The collective approach is best, but not always available.

- Verification of all information is needed.

- The actions of the CMT are scrutinized.

- Post-crisis decisions will be reviewed by everyone.

- Stakeholders want to be a part of the resolution process.

- Decisions have short-term effects.

- Decisions have long-term effects.

\section{Crisis Management Team Initial Crisis Briefings}

Should a crisis occur, the first person receiving notification of it should confer it to the Intelligence Coordinator. Then team assignments are made to confirm, clarify and verify current intelligence data. In the immediate action phase that follows, we need to determine:

- what must be done immediately to preserve lives and contain the situation;

- who should be deployed to the scene of the crisis;

- the Essential Elements of Information - who, what, where, when, why, how much, how little, how often;

- whether an off-site operational venue should be designated;

- should anyone from corporate headquarters be deployed to the crisis site;

- if specialized operational / support groups should be formed, briefed, or activated.

The deliberate planning phase designates the actions required to isolate and contain the incident. It involves strategic and continuing briefings for senior-level 
management and other corporate personnel who are aware of the situation, and developing documentation to capture all pertinent data related to this particular incident.

The essential elements of information comprise a threat assessment (what is known, what has happened, what are the damages or injuries and the imminent risk for further damages or injury, what are the cause(s) and alternative strategies), policy decisions (aimed to confirm the appropriate limits of what may be done and what will not be done) and strategy formulation (an overall strategy that should be pursued and separate strategies for media response, damage limitation, security, financial response, human resources).

At the resolution phase all components to resolve the crisis situation at the corporate, regional and international levels are coordinated. Eventually, the post-critical phase includes critiques/debriefings (oral and written) and psychological post-critical incident debriefings, as well as assigning personnel to secure all crisis incident documentation. A Post-Crisis Report is then elaborated that should emphasize the problems encountered, how those problems were addressed and how these problems will be addressed in future operations.

HARRY THOMAS "Bud" EVANS, a former Supervisory Special Agent with the Federal Bureau of Investigation, is the founder and President of H.T. Evans, Inc., a Crisis Management based organization affiliated with security missions for law enforcement, military and business personnel. A Managing Director for Kroll Associates from July 1999 through December 2001, Evans directed and coordinated the development of Crisis Management and Disaster Recovery Plans for domestic and international corporations. A former member of the FBI Critical Incident Response Group (CIRG), he coordinated the establishment of FBI Crisis Response Plans and Crisis Management Teams as well as assisted in the development of the position of Crisis Management Coordinator for all FBI field divisions. Mr. Evans, a twenty-seven year veteran of the FBI, is a Crisis / Hostage Negotiator, Bomb Technician, Firearms and Defensive Tactics Instructor and is well versed in the areas of fraud, extortion/kidnapping, domestic and international terrorism. He has been assigned as well as testified in numerous Crisis Management and international terrorist operations to include the World Trade Center bombing, 1993; the Oklahoma City bombing, 1995; the 81-day Freeman compound siege in Jordan, Montana, 1996; the Atlanta Olympic Park bombing, 1996; the U.S. Embassy bombings in Kenya and Tanzania, 1998; and was assigned to coordinating duties at a Crisis Command Center for FBI operations in Kosovo, the Republic of Yugoslavia. Mr. Evans has instructed in the areas of Crisis Management, Crisis/Hostage Negotiations and Tactical Operations throughout the United States, Europe, Africa, and the former Soviet Union. Address for correspondence: H.T. Evans, Inc. 11915 Kingswood Blvd., Fredericksburg, Virginia 22408, Fax: + 1540 891-9321. 